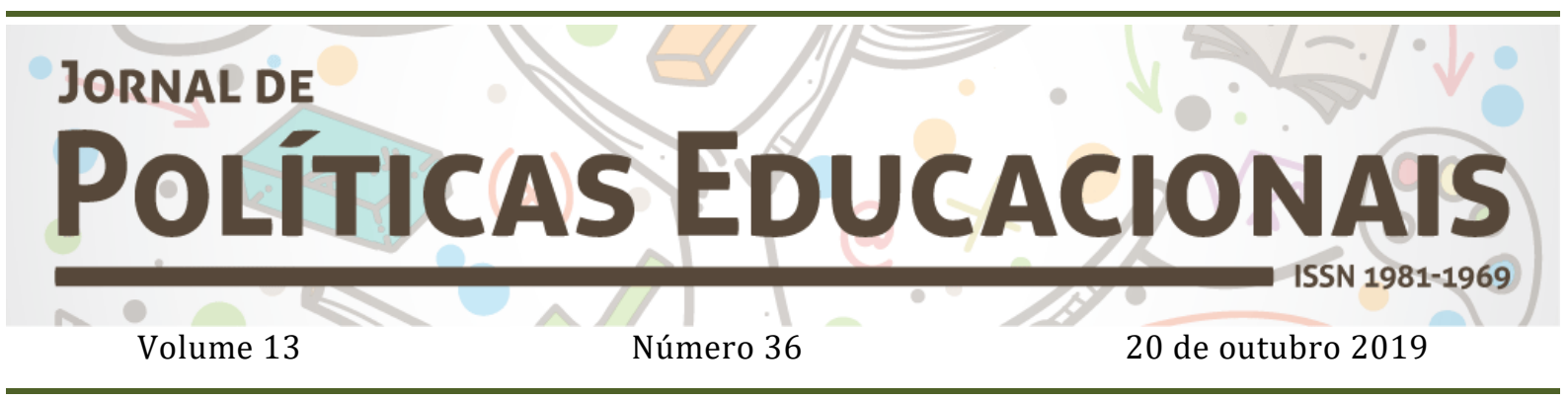

\title{
Avaliação da efetividade de uma política pública: ação afirmativa para a agricultura familiar no Campus Concórdia/IFC
}

\section{Evaluation of the effectiveness of a public policy: affirmative action for family agriculture in Campus Concordia/IFC}

\section{Evaluación de la efectividad de una política pública: acción afirmativa para la agricultura familiar en el Campus Concordia/IFC}

\author{
Francieli Marchesan ${ }^{1}$ \\ Oséias Santos de Oliveira ${ }^{2}$
}

Citação: MARCHESAN, F; OLIVEIRA, O, S. de. Avaliação da efetividade de uma política pública: ação afirmativa para a agricultura familiar no Campus Concórdia/IFC. Jornal de Políticas Educacionais. V. 13, n. 36. Outubro de 2019.

http:// 10.5380/ipe.v13i0.65637

Resumo: As políticas públicas implementadas no Brasil visam, principalmente, a redução das desigualdades sociais e a melhoria da qualidade de vida da população, sendo que grande parte delas voltamse à educação, por sua influência no desenvolvimento socioeconômico do país. Para a melhor gestão e otimização destas ações, são necessárias avaliações constantes dos resultados alcançados. Nesse sentido, este trabalho objetiva analisar a efetividade da ação afirmativa para a agricultura familiar implementada pelo Campus Concórdia/IFC, para o curso Técnico em Agropecuária. A metodologia pauta-se em uma pesquisa quali-quantitativa, de um estudo de caso, utilizando-se para coleta de dados a análise dos documentos nacionais e institucionais que balizam as cotas sociais. Como resultado, verificou-se que a política desenvolvida é efetiva, por intervir positivamente na realidade da população-alvo. Considera-se a

\footnotetext{
${ }^{1}$ Mestrado Profissional em Administração Pública pela UTFPR. Servidora do IFC. Lotada no Campus Concórdia, no setor de Pesquisa Institucional - Departamento de Ensino. Orcid: https://orcid.org/00000001-5928-9767 E-mail: fran.marchesan@bol.com.br Concórdia. Paraná. Brasil.

2 Doutor em Educação. Professor Adjunto do Departamento de Educação da Universidade Tecnológica Federal do Paraná/Curitiba (UTFPR) e Docente do Programa Mestrado Profissional em Administração Pública em Rede Nacional (PROFIAP/UTFPR). Superintendente Executivo da Secretaria Municipal da Educação de Curitiba. Orcid: https://orcid.org/0000-0002-7975-386X E-mail: oseiass@utfpr.edu.br Curitiba. Paraná. Brasil.
} 
ação afirmativa assertiva, pois esta representa uma medida fundamental para a inclusão sócio educacional de estudantes provenientes da atividade agrícola.

Palavras-chave: Políticas Públicas. Cotas Sociais. Agricultura Familiar. Avaliação de Efetividade.

\begin{abstract}
The public policies implemented in Brazil are mainly aimed at reducing social inequalities and improving the population's quality of life, and most of them focus on education, because of their influence on the socioeconomic development of the country. For the best management and optimization of these actions, constant evaluations of the achieved results are necessary. In this sense, this paper aims to analyze the effectiveness of affirmative action for family farming implemented by Campus Concordia/IFC, into Technical Course in Agriculture. The methodology is based on a qualitative and quantitative research of a case study, using for data collection the analysis of national and institutional documents that guide the social quotas. As a result, it was found that the policy developed is effective because it positively intervenes in the reality of the target population. The affirmative action is considered assertive because represents a fundamental measure for the social and educational inclusion of students coming from the agricultural activity.
\end{abstract}

Keywords: Public Policies. Social Quotas. Family Farming. Effectiveness Evaluation.

Resumen: Las políticas públicas implementadas en Brasil tienen como objetivo principal reducir las desigualdades sociales y mejorar la calidad de vida de la población, y la mayoría de ellas se centran en la educación, debido a su influencia en el desarrollo socioeconómico del país. Para la mejor gestión y optimización de estas acciones, son necesarias evaluaciones constantes de los resultados obtenidos. En este sentido, este trabajo tiene como objetivo analizar la efectividad de la acción afirmativa para la agricultura familiar implementada por Campus Concordia/IFC, para el Curso Técnico en Agricultura. La metodología se basa en una investigación cualitativa y cuantitativa de un estudio de caso, utilizando para la recopilación de datos el análisis de documentos nacionales e institucionales que guían las cuotas sociales. Como resultado, se descubrió que la política desarrollada es efectiva porque interviene positivamente en la realidad de la población objetivo. Se considera la acción afirmativa asertiva, ya que representa una medida fundamental para la inclusión social y educativa de los estudiantes provenientes de la actividad agrícola.

Palabras clave: Políticas Públicas. Cuotas Sociales. Agricultura Familiar. Evaluación de Efectividad.

\title{
Introdução
}

No Brasil, essencialmente nas três últimas décadas, expandiu-se a implementação de políticas públicas, principalmente em razão da Constituição Federal de 1988, que institui um cardápio variado de direitos sociais. A educação, nesse contexto, passou a ser percebida, dentro do grande espectro de políticas públicas, como essencial, pois além de ser um direito de todos, revela-se como elemento capaz de contribuir para o desenvolvimento social e humano.

As principais políticas educacionais, recentemente implementadas, visam à promoção da equidade no acesso e permanência dos alunos nas instituições de ensino. Nesse bojo de reestruturação e ampliação da oferta de educação pública, inseriram-se os Institutos Federais de Educação, Ciência e Tecnologia - IFET(s), que têm sua demanda de oferta de cursos pautada no âmbito de cursos técnicos e tecnológicos, mas também superiores. 
Nesse sentido, este estudo trata, mais espeficamente, da política pública de ação afirmativa de cotas sociais, criada em benefício de determinados grupos, para acesso aos cursos de universidades federais e IFETs. Apesar de as cotas sociais já serem adotadas por algumas universidades desde os primeiros anos da década de 2000, apenas no ano de 2012, com a promulgação da Lei no $12.711 / 2012$, tal medida tornou-se obrigatória nas instituições federais (BRASIL, 2012a).

Além das cotas previstas na referida lei, facultou-se às instituições públicas federais a criação de reserva de vagas suplementares, por meio de políticas específicas de ações afirmativas, nos termos do Decreto n 7.824/2012 (BRASIL, 2012b) e da Portaria Normativa nº 18/2012 do Ministério da Educação - MEC (BRASIL, 2012c).

Com base nesses dispositivos, o Instituto Federal de Educação, Ciência e Tecnologia Catarinense (IFC) criou, no ano de 2013, uma ação afirmativa específica, direcionada à agricultura familiar, reservando 25\% das vagas disponibilizadas para o curso Técnico em Agropecuária, para o ingresso de estudantes provenientes da atividade agrícola (IFC, 2013a; IFC, 2013b).

Todas as políticas públicas, tanto as de nível nacional quanto as de abrangência mais local (como é o caso da ação afirmativa criada pelo IFC), devem passar por avaliações constantes, até porque a avaliação é uma das etapas do seu ciclo de implementação. A avaliação de uma política pública representa um importante instrumento de gestão, permitindo a verificação dos impactos e efeitos desejados ou indesejados, a definição quanto às ações e programas futuros (FREY, 2000), assim como a otimização de recursos públicos aplicados, o controle sobre as ações governamentais e a divulgação de resultados à sociedade (CUNHA, 2006).

Diante do exposto, destaca-se que o objetivo deste estudo é analisar a efetividade da política pública de ação afirmativa para a agricultura familiar implementada pelo Campus Concórdia/IFC, para acesso ao curso Técnico em Agropecuária. Essa análise volta-se para uma perspectiva de inclusão social e educacional, considerando as mudanças nas condições de vida da população-alvo, pautada na inserção dos estudantes egressos no mercado de trabalho e no prosseguimento de estudos.

Além da necessidade já citada das políticas públicas serem avaliadas, por ser essa uma etapa de seu ciclo, essencial para fins de gestão e tomada de decisão, justifica-se a realização desta pesquisa, principalmente, pela ausência de avaliações sobre a política de cotas implementada pela instituição. 


\section{Cotas Sociais: uma Política Pública de Ação Afirmativa}

Nas últimas décadas, a implementação de políticas públicas sociais tem aumentado consideravelmente no país, principalmente a partir da promulgação da Constituição Federal de 1988, que, com seus princípios expressos, dá a entender que o Brasil se dispõe a ser um Estado Social (SILVA; TORELLY; MADEIRA, 2008). Na ânsia de efetivar tal condição, o Estado passou a adotar políticas públicas voltadas para a redução do distanciamento entre os diferentes setores da sociedade, protegendo a cidadania e efetivando os direitos sociais (SILVA; TORELLY; MADEIRA, 2008).

Dentre os setores atendidos pelas políticas sociais, a de educação recebe especial atenção, tendo em vista que, além de ser um direito de todos e de sinalizar para a construção de uma sociedade mais igual e humana (CURY, 2002), a educação é considerada essencial para o desenvolvimento socioeconômico de uma nação (MELLO, 1991). Linhares (2010) complementa citando que esse destaque é devido à constatação de que a desigualdade educacional é o principal correspondente da desigualdade de renda, de oportunidades e de condição de vida de uma população.

As principais ações recentemente implementadas no país, na área educacional, visam promover o acesso mais equitativo às instituições de ensino superior, destacandose a educação a distância, as políticas governamentais por meio de financiamentos (Fundo de Financiamento Estudantil - Fies, e o Programa Universidade para Todos - Prouni) e as cotas sociais (CAMPOS et al., 2016).

O enfoque deste estudo volta-se para a discussão das ações afirmativas, consubstanciadas nas cotas para acesso ao ensino público. Ação afirmativa é um termo de amplo alcance, que pode designar um conjunto de estratégias, políticas ou iniciativas, que buscam favorecer determinados grupos sociais que se encontram em condições de competição menos favorecidas, na maioria das vezes, em razão da prática de discriminações negativas, passadas ou presentes (MENEZES, 2001).

Essas ações buscam a superação de uma defasagem histórica existente no Brasil em relação às minorias (ANCHIETA, 2008). Bezerra e Gurgel (2012) defendem que as ações afirmativas não são sustentadas na ideia de promoção de privilégios aos pobres, muito pelo contrário. Para eles, as ações afirmativas têm como ideal oferecer oportunidades, pois os grupos beneficiados não partem do mesmo ponto dos mais 
privilegiados e, neste caso, não possuem as mesmas facilidades para ingressar em universidades ou no mercado de trabalho, por exemplo.

McCowan (2007) explica que a implementação do sistema de cotas no Brasil não foi inicialmente uma política pública, mas, sim, uma resposta individual de universidades às demandas de grupos sociais, causando, posteriormente, um debate nacional e, a partir de então, a inclusão do assunto na agenda do governo federal.

O grande marco legal para a implementação dessa política foi a promulgação da Lei $\mathrm{n}$ - 12.711/2012, a Lei das Cotas, dispondo que as universidades federais e as instituições federais de ensino técnico de nível médio deveriam reservar em cada processo seletivo de ingresso, no mínimo, 50\% das vagas para estudantes que cursaram, integralmente, o ensino fundamental ou médio, conforme o caso, em escolas públicas (BRASIL, 2012a).

As vagas para os alunos oriundos de escolas públicas ainda são subdivididas: $50 \%$ para estudantes de famílias com renda igual ou inferior a 1,5 salários-mínimos per capita, por autodeclarados pretos, pardos e/ou indígenas, e por pessoas com deficiência, "em proporção ao total de vagas no mínimo igual à proporção respectiva de pretos, pardos, indígenas e pessoas com deficiência na população da unidade da Federação onde está instalada a instituição", segundo o último censo do Instituto Brasileiro de Geografia e Estatística - IBGE (BRASIL, 2012a, [n.p.]).

\section{Avaliação da Efetividade de uma Política Pública}

A etapa da avaliação compõe o ciclo de implementação de uma política pública e possui grande relevância para a gestão governamental, subsidiando o planejamento e a formulação de intervenções do governo, assim como o acompanhamento da implementação, as reformulações e ajustes, e as decisões sobre a manutenção ou não de atividades (CUNHA, 2006).

Figueiredo e Figueiredo (1986) entendem que avaliar é aplicar valor, determinando se algo é bom ou ruim. Segundo eles, é preciso estabelecer critérios de avaliação que permitam garantir se e porquê uma política pode ser preferível à outra. Os autores alertam, contudo, que, se a política envolver princípios políticos baseados na concepção de bem-estar do ser humano, a avaliação sempre terá um caráter mais controverso e complexo (FIGUEIREDO; FIGUEIREDO, 1986). 
Arretche (2009) destaca que a literatura costuma dividir a avaliação de políticas públicas em termos de efetividade, eficiência e eficácia. Destaca-se, porém, que, neste estudo, será analisada apenas a efetividade da política pública de ação afirmativa para a agricultura familiar, implementada pelo Campus Concórdia/IFC.

A avaliação da efetividade é a análise da relação entre a prática de implementação de um programa e seus resultados, ou seja, do sucesso ou do fracasso no que se refere às mudanças nas condições sociais de vida das sociedades atingidas pela política avaliada (FIGUEIREDO; FIGUEIREDO, 1986). É na avaliação da efetividade que se distingue os produtos de uma política pública e seus resultados (ARRETCHE, 2009).

Sano e Montenegro Filho (2013) corroboram destacando que a efetividade está mais relacionada ao impacto de um programa social, procurando identificar os resultados produzidos sobre a população envolvida. Avaliar o impacto social, de acordo com eles, é mensurar o verdadeiro valor de um investimento social, sendo que a principal dificuldade nesta avaliação está em garantir a relação entre as ações e as mudanças percebidas.

Na concepção de Figueiredo e Figueiredo (1986), uma política obtém sucesso (é efetiva) quando se imputa a ela a condição de causa necessária -senão suficiente - de uma mudança constatada, isto é, não se pode concluir pelo sucesso do programa apenas pela constatação de que houve mudança. Assim, é necessário demonstrar que essa mudança não teria ocorrido (total ou parcialmente) sem o programa (FIGUEIREDO E FIGUEIREDO, 1986).

\section{O IFC, o Campus Concórdia, o Curso Técnico em Agropecuária e a Ação Afirmativa para a Agricultura Familiar}

O Instituto Federal de Educação, Ciência e Tecnologia Catarinense (IFC), campo deste estudo, localiza-se no estado de Santa Catarina. Desde a sua criação, o IFC sempre se assinalou com uma identidade mais agroindustrial, estando próximo às demandas do interior, necessidades sociais e do campo (IFC, 2017a).

Em virtude de sua característica multicampi, o IFC é formado, atualmente, pela Reitoria e mais 15 campi, sendo eles: Campus Araquari, Campus Blumenau, Campus Brusque, Campus Camboriú, Campus Concórdia, Campus Avançado Abelardo Luz, Campus Fraiburgo, Campus Ibirama, Campus Luzerna, Campus Rio do Sul, Campus São Bento do Sul, Campus Santa Rosa do Sul, Campus Avançado Sombrio, Campus São Francisco do Sul e Campus Videira (IFC, 2017b). 
A instituição disponibiliza educação em todos os níveis e modalidades. No ano de 2017, foram ofertados: 54 cursos técnicos de nível médio; 38 cursos de graduação, no nível superior; 6 cursos do Programa de Educação de Jovens e Adultos Integrados à Educação Profissional; 12 cursos de pós-graduação lato sensu; e, 1 curso de pósgraduação stricto sensu (IFC, 2018). Nesse mesmo exercício, o IFC atendeu a cerca de 11 mil alunos (regularmente matriculados), contando com um quadro de cerca de 2 mil servidores - entre docentes e técnicos administrativos (IFC, 2018).

Quanto ao Campus Concórdia, foi implantado ainda em março de 1965, por meio do Decreto $\mathrm{n}^{\mathrm{0}}$ 60.731/67, formando a primeira turma no ano de 1968. Com o Decreto $\mathrm{n}$ o 83.935/79, tornou-se a Escola Agrotécnica Federal de Concórdia. Pela Lei ํo 8.731/93, transformou-se em Autarquia Federal, vinculada ao MEC. Com a promulgação da Lei 11.892/2008 passou a ser o Campus Concórdia/IFC (IFC-CONCÓRDIA, 2017a).

O Campus Concórdia está situado na cidade de Concórdia, na região Oeste de Santa Catarina. Os principais arranjos produtivos dessa região são: a) na agricultura: cultivo de soja, milho, trigo e feijão; b) na pecuária: bovinocultura leiteira e de corte, avicultura e suinocultura; c) extração de madeira; e d) agroindústrias (SANTA CATARINA, 2016).

A região Oeste de Santa Catarina se caracteriza pela forte presença da agricultura familiar, contando com mais de 73 mil estabelecimentos desse gênero, correspondentes a quase $44 \%$ do total existente no estado (IBGE, 2010). Como os demais municípios da região, Concórdia conta com a forte presença das agroindústrias familiares e de pequenos produtores rurais (PORTAL DO CIDADÃO, 2017).

Os cursos ofertados pelo campus são (IFC-CONCÓRDIA, 2017b): a) Técnico (Nível Médio): Agropecuária, Alimentos, Informática para Internet; b) Bacharelado: Engenharia de Alimentos, Medicina Veterinária, Agronomia; c) Licenciatura: Física, Matemática; d) Pós-graduação: Mestrado em Produção e Sanidade Animal e Especialização em Educação Matemática.

O curso Técnico em Agropecuária é o curso mais antigo do Campus Concórdia/IFC. A implantação de uma escola técnica nessa cidade, bem como a criação de um curso Técnico em Agropecuária, deu-se em virtude das demandas da região de Concórdia, que, desde a década de 1960, tinha como base da sua economia a agricultura e a produção de suínos (SANTOS et al., 2015). Nos dias atuais, nos termos do Projeto Pedagógico do Curso (PPC), as demandas do setor agropecuário da região de Concórdia, do estado de Santa 
Catarina e até mesmo do Brasil, ainda geram a necessidade da formação anual de um número expressivo de Técnicos em Agropecuária (IFC-CONCÓRDIA, 2015).

Nesse sentido, o curso Técnico em Agropecuária, ofertado pelo Campus Concórdia/IFC, tem por objetivo proporcionar aos estudantes uma formação profissional sólida, tornando-os aptos para atuarem nessas diversas áreas, bem como possibilitar o prosseguimento dos estudos (IFC-CONCÓRDIA, 2015).

A ação afirmativa para a agricultura familiar, adotada pelo campus para o acesso ao curso Técnico em Agropecuária, foi desenvolvida por meio da Resolução Ad referendum no 021 - CONSUPER/IFC/2013 (IFC, 2013a), ratificada pela Resolução no 048 CONSUPER/IFC/2013 (IFC, 2013b), aprovada pelo Conselho Superior (Consuper) do IFC. Tal medida determinou que a instituição passasse a adotar uma reserva de vagas para candidatos provenientes da atividade agrícola, como uma ação afirmativa específica da instituição (IFC, 2013b). Essa reserva, de acordo com a referida resolução, corresponde a $25 \%$ do total das vagas dos cursos técnicos (integrados e subsequentes) em agropecuária (IFC, 2013b).

O amparo legal para a criação dessa ação afirmativa específica pelo IFC é a própria Lei no 12.711/2012 (BRASIL, 2012a), e, mais precisamente, o Decreto no 7.824/2012 (BRASIL, 2012b), e a Portaria Normativa no 18/2012 - MEC (BRASIL, 2012c), que regulamentam a Lei de Cotas e autorizam as instituições de ensino a implantarem reserva de vagas suplementares ou de outra modalidade, por meio de políticas específicas de ações afirmativas.

Apesar de as resoluções aprovadas pelo Consuper do IFC não explicitarem uma motivação para a criação dessa cota específica, Marchesan e Oliveira (2017) inferem que ela foi criada em atendimento ao Acordo de Metas e Compromissos (TAM), celebrado entre a Setec/MEC e o IFC. Nesse acordo, foi fixado, dentre outros, o compromisso de o IF adotar "formas de acesso assentadas em ações afirmativas que contemplem as realidades locais dos campi [...]" (SETEC/MECXIFC, 2010, p. 4). Dessa forma, segundo os autores, a opção pela agricultura familiar se deu em virtude de o IFC, desde sua implantação, possuir uma identidade mais agroindustrial, associada às demandas do interior e demandas sociais. Além disso, em razão de o município de Concórdia, assim como toda a região Oeste do estado de Santa Catarina, caracterizar-se pela forte presença de agroindústrias familiares e de pequenos produtores rurais (MARCHESAN; OLIVEIRA, 2017). 


\section{Procedimentos Metodológicos}

A metodologia empregada neste estudo pauta-se por uma pesquisa qualiquantitativa, realizada por meio de um estudo de caso institucional, utilizando-se, como instrumentos para coleta de informações e dados, a análise documental.

Para atendimento do objetivo proposto, mais precisamente, foi analisado, primeiramente, o desempenho dos alunos no processo seletivo de ingresso. A coleta de dados foi feita por meio da documentação dos Exames de Classificação, comparando o desempenho (nota) dos alunos optantes pela cota da agricultura familiar com o desempenho (nota) dos alunos aprovados pela ampla concorrência, para fins de constatação de causa necessária/suficiente do programa.

Na sequência, foi efetuado o cálculo do índice de inserção dos alunos egressos no mercado de trabalho e/ou do prosseguimento dos estudos, que, além de serem os objetivos do curso Técnico em Agropecuária do Campus Concórdia/IFC, são fatores que podem interferir na condição de vida da população atingida. A coleta de dados deu-se por meio dos estudos de egressos desenvolvidos pela própria instituição/campus (também serão comparados os resultados dos ingressantes pela cota da agricultura familiar com os da ampla concorrência).

Em se tratando da definição da população e amostra, ressalta-se que não foram considerados os dados dos alunos optantes/beneficiados pelas cotas estabelecidas pela Lei no 12.711/2012, por motivo de limitação da pesquisa. Da mesma forma, como os alunos ingressantes em 2016, 2017 e 2018 ainda não finalizaram o ciclo de três anos do curso - tempo mínimo para a integralização curricular (IFC-CONCÓRDIA, 2015) -, o presente estudo trabalhou apenas com os ingressantes em 2014 e 2015 (ciclos já finalizados).

\section{Análise e Discussão dos Dados}

Para embasar a análise, primeiramente, foram levantados os resultados (desempenho/nota) dos alunos nos processos seletivos de ingresso. Propôs-se a investigação desses dados considerando que o resultado poderia ser um indicador do sucesso da política, ao demonstrar sua condição de causa necessária de uma mudança constatada. 
Relembrando Figueiredo e Figueiredo (1986), uma política obtém sucesso (é efetiva) quando se imputa a ela a condição de causa necessária - senão suficiente - de uma mudança constatada. Segundo eles, não se poderia concluir pelo sucesso apenas pela constatação de que houve mudança, sendo necessário demonstrar que essa melhoria não teria ocorrido (total ou parcialmente) sem o programa.

Nesse sentido, a análise do desempenho nos processos seletivos poderia demonstrar se tais alunos somente são aprovados nas vagas reservadas à cota ou se alguns deles conseguem ingressar nas vagas da ampla concorrência (melhores notas). $\mathrm{Ou}$ seja, poderia ser um indicativo da condição de causa necessária ou não da mudança constatada, evidenciando se os estudantes provenientes da atividade agrícola conseguem ingressar no curso e, consequentemente, terem as mesmas oportunidades, do ponto de partida, sem necessitarem da política implementada.

Partindo para a análise, de fato, buscou-se nos relatórios dos processos de seleção, mais precisamente, nas relações de inscritos e dos resultados obtidos na prova, o desempenho dos candidatos. Todavia, foi constatado que, nos relatórios dos processos de seleção disponíveis no Campus Concórdia e na Reitoria do IFC, na relação dos candidatos inscritos, não havia a especificação, por candidato, da opção por uma ação afirmativa ou pela ampla concorrência. Assim, não foi possível identificar se algum dos candidatos, inscritos na ação afirmativa da agricultura familiar, obteve desempenho suficiente para ser aprovado nas vagas da ampla concorrência.

A ausência desses dados prejudicou a análise do indicador não sendo possível verificar a condição de causa necessária/suficiente do programa, nos termos propostos. Mesmo assim, expõem-se na sequência os dados encontrados.

Como os candidatos que obtêm as melhores notas, independentemente da opção por cotas, são aprovados pela ampla concorrência, seu desempenho será sempre superior àqueles que foram aprovados pelas vagas reservadas à cota da agricultura familiar.

Como se verifica na Tabela 1, no Exame de Classificação 2014, houve um total de 334 inscritos, não podendo se especificar quantos destes se inscreveram na ação afirmativa da agricultura familiar. Com base nos dados levantados, constata-se que o desempenho (nota média) dos alunos aprovados pela ampla concorrência foi de 6,19, enquanto que o resultado alunos aprovados pela cota da agricultura familiar foi de 4,43. 
Tabela 1. Desempenho dos candidatos aprovados no Exame de Classificação para ingresso em 2014

\begin{tabular}{lcccccc}
\hline Vaga/ingresso & $\begin{array}{c}\text { No } \\
\text { Inscritos }\end{array}$ & $\begin{array}{c}\text { No } \\
\text { Aprovados }\end{array}$ & $\begin{array}{c}\text { Nota } \\
\text { Mínima }\end{array}$ & $\begin{array}{c}\text { Nota } \\
\text { Máxima }\end{array}$ & $\begin{array}{c}\text { Nota } \\
\text { Média }\end{array}$ & $\begin{array}{c}\text { Aprovados } \\
\text { pela AC }\end{array}$ \\
\hline Agricultura Familiar & $\begin{array}{c}\text { ausência } \\
\text { de dados }\end{array}$ & 15 & 3,4 & 5,2 & 4,43 & $\begin{array}{c}\text { ausência de } \\
\text { dados }\end{array}$ \\
\hline Ampla Concorrência & 334 & 35 & 5,6 & 7,4 & 6,19 & - \\
\hline
\end{tabular}

Legenda: AC - Ampla Concorrência.

Fonte: Elaborado pelos autores (2018) com base nos relatórios dos processos seletivos do IFC.

As notas dos candidatos selecionados nesse processo foram, de maneira geral, baixas. Chama-se a atenção para a diferença da média de desempenho dos alunos aprovados pela cota da agricultura familiar (1,76 pontos), comparada à média da ampla concorrência, e também para a nota mínima de 3,4 obtida pelo(s) candidato(s) aprovado(s).

Tabela 2. Desempenho dos candidatos aprovados no Exame de Classificação para ingresso em 2015

\begin{tabular}{lcccccc}
\hline Vaga/ingresso & $\begin{array}{c}\text { No } \\
\text { Inscritos }\end{array}$ & $\begin{array}{c}\text { No } \\
\text { Aprovados }\end{array}$ & $\begin{array}{c}\text { Nota } \\
\text { Mínima }\end{array}$ & $\begin{array}{c}\text { Nota } \\
\text { Máxima }\end{array}$ & $\begin{array}{c}\text { Nota } \\
\text { Média }\end{array}$ & $\begin{array}{c}\text { Aprovados } \\
\text { pela AC }\end{array}$ \\
\hline Agricultura Familiar & $\begin{array}{c}\text { ausência } \\
\text { de dados }\end{array}$ & 26 & 3,33 & 7,0 & 5,33 & $\begin{array}{c}\text { ausência de } \\
\text { dados }\end{array}$ \\
\hline Ampla Concorrência & 256 & 35 & 7,0 & 9,0 & 7,52 & - \\
\hline
\end{tabular}

Fonte: Elaborado pelos autores (2018) com base nos relatórios dos processos seletivos do IFC.

Quanto ao Exame de Classificação 2015, houve um total de 256 inscritos. Nesse ano, a nota média dos alunos aprovados pela ampla concorrência foi de 7,52, enquanto que o daqueles optantes pela cota da agricultura familiar foi de 5,33. Comparando-se o desempenho dos candidatos por condição, nos dois processos, percebe-se que houve uma melhora na nota média de 2014 para 2015. Contudo, a diferença entre as médias também aumentou, chegando a 2,19 pontos, e, novamente, a nota mínima obtida pelo(s) candidato(s) aprovado(s) pela ação afirmativa na prova foi bem baixa $(3,33)$. No Gráfico 1 consta a comparação, por condição: 


\section{Gráfico 1. Comparação entre o desempenho nos processos de ingresso, por condição}

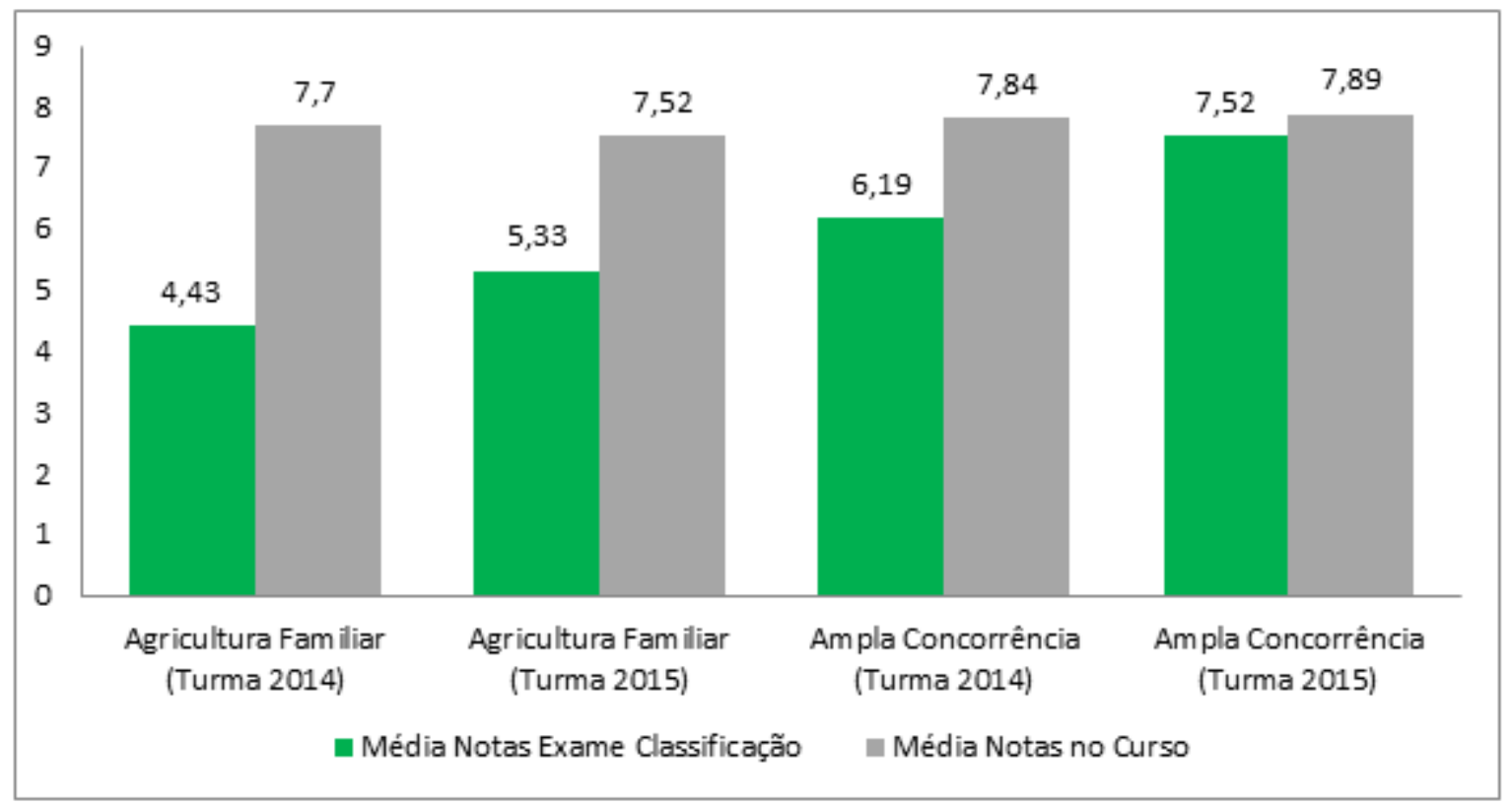

Fonte: Elaborado pelos autores (2018) com base nos relatórios dos processos seletivos.

Apesar da análise desse indicador ter sido prejudicada pela ausência de dados, pode-se considerar, de certa forma, a condição de causa necessária da política implementada, pois verifica-se que, senão todos, muitos dos candidatos inscritos nas vagas destinadas à agricultura familiar somente ingressam no curso Técnico em Agropecuária do Campus Concórdia, tendo em vista a existência da cota desenvolvida pela instituição.

Ainda para a avaliação da efetividade da cota para a agricultura familiar, considerou-se, neste estudo, que fatores como a inserção dos alunos egressos (Técnicos Agrícolas) no mercado de trabalho e/ou o prosseguimento dos estudos, além de serem os principais objetivos do curso, podem proporcionar mudanças na condição de vida, tanto dos próprios estudantes beneficiados pela política como de todo o seu entorno.

Para a análise desse indicador, este trabalho aproveitou-se dos estudos de egressos desenvolvidos pela Política de Acompanhamento de Egressos (PAEG) da própria instituição. Os dados levantados, em relação aos alunos egressos do Campus Concórdia, estão dispostos nas Tabelas 3 e 4: 
Tabela 3. Dados dos egressos, ingressantes 2014

\begin{tabular}{|c|c|c|c|c|c|c|c|c|}
\hline $\begin{array}{c}\text { Vaga/ } \\
\text { Ingresso }\end{array}$ & Formandos & $\begin{array}{l}\text { Partici- } \\
\text { pantes }\end{array}$ & $\begin{array}{l}\text { Mercado } \\
\text { Trabalho }\end{array}$ & $\%$ & $\begin{array}{c}\text { Continui- } \\
\text { dade dos } \\
\text { Estudos }\end{array}$ & $\%$ & Outros & $\%$ \\
\hline $\begin{array}{l}\text { Agricultura } \\
\text { Familiar } \\
\text { (egressos } \\
2016 \text { ) }\end{array}$ & 6 & 6 & 2 & $33,33 \%$ & 4 & $66,67 \%$ & 0 & - \\
\hline $\begin{array}{l}\text { Ampla } \\
\text { Concorrência } \\
\text { (egressos } \\
2016 \text { ) }\end{array}$ & 30 & 29 & 4 & $13,79 \%$ & 20 & $68,97 \%$ & 5 & $17,24 \%$ \\
\hline
\end{tabular}

Fonte: Elaborado pelos autores (2018) com base nos registros escolares dos alunos/turmas.

No que se refere aos alunos egressos de 2016, correspondentes à maioria dos alunos ingressantes em 2014, verifica-se que todos os concluintes oriundos da cota para a agricultura familiar atingiram pelo menos um dos principais objetivos do curso. Ou seja, conforme exposto na Tabela $3,66,67 \%$ dos estudantes deram continuidade aos seus estudos em cursos superiores e 33,33\% declararam já estar inseridos no mercado de trabalho.

A colaboração na pesquisa dos alunos ingressantes pela ampla concorrência também foi muito significativa $(96,67 \%$ dos egressos), revelando que $82,76 \%$ deles atingiram pelo menos um dos principais objetivos do curso $(68,97 \%$ deram continuidade aos estudos em cursos superiores e 13,79\% já estavam inseridos no mercado de trabalho). Porém, 17,24\% dos respondentes declararam não estar nem estudando e nem trabalhando após o término do curso.

Tabela 4. Dados dos egressos, ingressantes 2015

\begin{tabular}{|c|c|c|c|c|c|c|c|c|}
\hline $\begin{array}{l}\text { Vaga/ } \\
\text { ingresso }\end{array}$ & Formandos & $\begin{array}{c}\text { Partici- } \\
\text { pantes }\end{array}$ & $\begin{array}{l}\text { Mercado } \\
\text { Trabalho }\end{array}$ & $\%$ & $\begin{array}{l}\text { Continui- } \\
\text { dade dos } \\
\text { Estudos } \\
\end{array}$ & $\%$ & Outros & $\%$ \\
\hline $\begin{array}{l}\text { Agricultura } \\
\text { Familiar } \\
\text { (egressos } \\
\text { 2017) }\end{array}$ & 12 & 12 & 1 & $8,33 \%$ & 9 & $75 \%$ & 2 & $16,67 \%$ \\
\hline $\begin{array}{l}\text { Ampla } \\
\text { Concorrência } \\
\text { (egressos } \\
2017 \text { ) }\end{array}$ & 32 & 32 & 1 & $3,12 \%$ & 28 & $87,5 \%$ & 3 & $9,38 \%$ \\
\hline
\end{tabular}

Fonte: Elaborado pelos autores (2018) com base nos registros escolares dos alunos/turmas.

Em se tratando dos alunos egressos de 2017 (maioria dos ingressantes de 2015), 83,33\% dos estudantes beneficiados pela cota da agricultura familiar atingiram, pelo menos, um dos objetivos do curso (75\% deram continuidade aos estudos e 8,33\% 
inseriram-se no mercado de trabalho). Os demais, 16,67\%, responderam não estar nem estudando e nem trabalhando. Destaca-se a participação integral dos alunos cotistas na pesquisa desenvolvida pelo campus, nos dois anos.

A participação dos discentes ingressantes pela ampla concorrência também foi integral nesse ano, revelando que $90,62 \%$ deles atingiram, pelo menos, um dos principais objetivos do curso $(87,5 \%$ deram continuidade aos estudos e 3,12\% inseriram-se no mercado de trabalho). Novamente, uma parcela desses egressos, correspondente a 9,38\%, respondeu não estar nem estudando e nem trabalhando após o término do curso.

Comparando os resultados das duas turmas, ingressantes de 2014 e de 2015, percebe-se que a grande maioria dos alunos formados opta por dar continuidade aos estudos, até mesmo os estudantes oriundos da atividade agrícola, ao invés de já se inserirem no mercado de trabalho. Isto pode ser observado no Gráfico 2.

\section{Gráfico 2. Comparação egressos (ingressantes em 2014 e 2015), por condição}

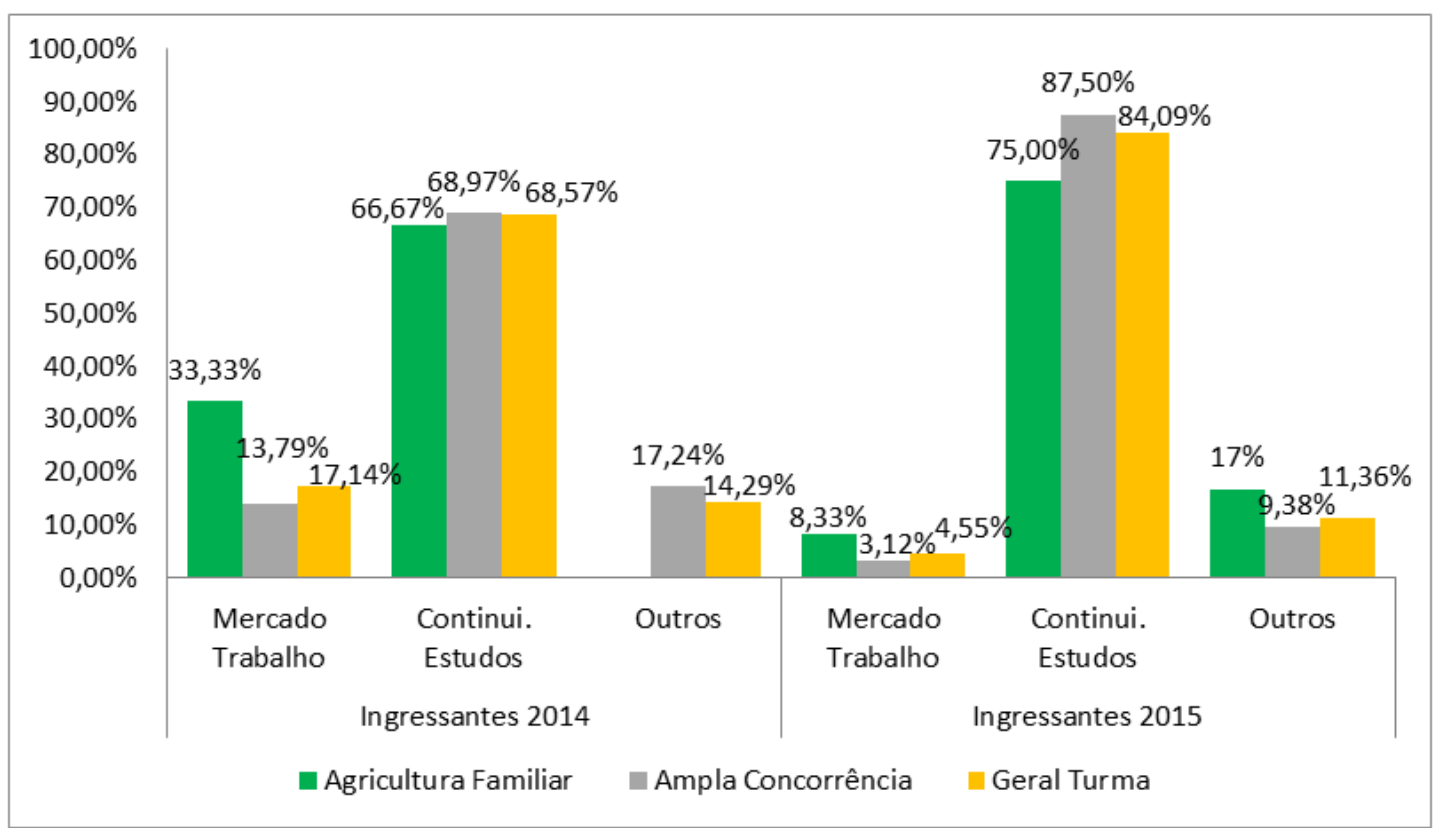

Fonte: Elaborado pelos autores (2018) com base nos dados dos estudos de egressos da instituição.

É oportuno destacar a parcela dos estudantes egressos que declarou não estar trabalhando e nem estudando após o término do curso. Em relação à média da turma dos egressos de 2016, o percentual foi de 14,29\% (somente alunos da ampla concorrência), enquanto que dos concluintes de 2017 foi de 11,36\% (alunos optantes pela ampla concorrência e pela cota da agricultura familiar). 


\section{Considerações Finais}

A importância das políticas públicas é inegável, pois estas representam tanto as respostas quanto o descaso do governo, voltadas ao atendimento das necessidades da sociedade. Tendo em vista a grande diversidade de políticas públicas, a escassez de recursos, bem como os diferentes interesses entre os mais variados grupos sociais, entende-se como fundamental a participação da população em todo o processo de implementação de uma política, para fins de controle da ação estatal.

Apesar de sua notória importância, as cotas sociais, para acesso ao ensino público, somente foram implementadas com a Lei no $12.711 / 2012$, que fez parte de um pacote de ações do governo que visavam ampliar a oferta de educação pública e a promoção da equidade no acesso e permanência dos alunos nas instituições de ensino. Seguindo esse mesmo rumo, o IFC acabou criando a ação afirmativa para a agricultura familiar, para acesso ao curso Técnico em Agropecuária, ainda no ano de 2013. Todavia, até então, não havia sido oportunizada nenhuma avaliação sobre tal política.

Como relatado, essa cota específica foi aprovada sem a publicação de qualquer motivação e nem a definição de objetivos e metas almejadas, sendo mais difícil, assim, analisar/avaliar se os seus resultados estão sendo bons ou ruins, ou determinar por seu sucesso ou fracasso (efetividade).

Mesmo assim, entende-se que o objetivo proposto para este estudo foi alcançado e que os resultados apresentados permitiram a análise da política de ação afirmativa para a agricultura familiar, implementada pelo Campus Concórdia/IFC para o curso Técnico em Agropecuária, inferindo-se que essa ação é efetiva.

Apesar da ausência de dados para a análise do desempenho dos alunos nos processos seletivos de ingresso, pode-se considerar a condição de causa necessária da cota da agricultura familiar, em virtude de que muitos estudantes oriundos da atividade agrícola somente conseguiram ingressar no curso pela existência dessa ação. A política desenvolvida também apresentou resultados muito significativos em relação à inserção dos egressos no mercado de trabalho e prosseguimento dos estudos após o término do curso.

Dessa forma, considera-se que a política desenvolvida é positiva e fundamental para a inclusão social e educacional dos estudantes provenientes da atividade agrícola. Esse grupo social possui uma histórica defasagem educacional e, no caso da cidade e 
região de localização do Campus Concórdia, representa uma parcela muito significativa da população.

Por fim, é preciso destacar que, apesar de ser muito difícil mensurar o ganho social de uma política pública, como a cota para a agricultura familiar, a avaliação da efetividade é essencial como instrumento de gestão e tomada de decisão, pois permite determinar medidas futuras capazes de aperfeiçoar as ações desenvolvidas e aumentar, nesse caso, o compromisso com a inclusão social e educacional.

\section{Referências}

ANCHIETA, K. A. História da Implantação do Sistema de Cotas para Negros na Universidade Estadual de Londrina - UEL (2000 - 2005). 2008. 144 f. Dissertação (Mestrado) - Curso de Mestrado em Educação, Universidade Estadual de Londrina, Londrina, 2008.

ARRETCHE, M. T. S.. Tendências no estudo sobre avaliação. In: RICO, Elizabeth M. (Org.). Avaliação de políticas sociais: uma questão em debate. São Paulo: Cortez, 2009. p. 29-39.

BEZERRA, T. O. C; GURGEL, C. R. M. A política pública de cotas na UERJ: desempenho e inclusão. In: ENCONTRO DE ADMINISTRAÇÃO PÚBLICA E GOVERNO, 1., 2012, Salvador. Anais... . Salvador: Anpad, 2012. p. 1 - 16. Disponível em: <http://www.anpad.org.br/admin/pdf/2012 EnAPG407.pdf>. Acesso em: 15 fev. 2018.

BRASIL. Lei n. 12.711, de 29 de agosto de 2012. Dispõe sobre o ingresso nas universidades e nas instituições federais de ensino técnico de nível médio e dá outras providências. Diário Oficial da República Federativa do Brasil, Brasília, DF, 30 ago. 2012 (a). Disponível em: <http://www.planalto.gov.br/ccivil 03/ ato20112014/2012/lei/l12711.htm>. Acesso em: 10 jan. 2018.

Decreto n. 7.824, de 11 de outubro de 2012. Regulamenta a Lei n. 12.711, de 29 de agosto de 2012, que dispõe sobre o ingresso nas universidades federais e nas instituições federais de ensino técnico de nível médio. Diário Oficial da República Federativa do Brasil, Brasília, DF, 15 out. 2012 (b). Disponível em: <http://www.planalto.gov.br/ccivil 03/ ato2011-2014/2012/decreto/D7824.htm>. Acesso em: 20 fev. 2018.

. Portaria Normativa no 18, de 11 de outubro de 2012, do Ministério da Educação. Dispõe sobre a implementação das reservas de vagas em instituições federais de ensino de que tratam a Lei no 12.711, de 29 de agosto de 2012, e o Decreto no 7.824, de 11 de outubro de 2012. Diário Oficial da República Federativa do Brasil, Brasília, DF, 15 out. 2012 (c). Disponível em: <http://portal.mec.gov.br/cotas/docs/portaria 18.pdf>. Acesso em: 20 fev. 2018.

CAMPOS, L. C. et al. Cotas sociais, ações afirmativas e evasão na área de negócios: análise empírica em universidade federal brasileira. Revista Contabilidade \& Finanças da 
USP, São Paulo, v. 28, n. 73, p. 27-42, jan./abr. 2016. Disponível em:

<http://www.Scielo.br/pdf/rcf/v28n73/pt 1808-057X-rcf-1808-057x201702590.pdf>. Acesso em: 05 jan. 2018.

CUNHA, C. G. S. da. Avaliação de Políticas Públicas e Programas Governamentais: tendências recentes e experiências no Brasil. George Washington University: Programa Minerva, Washington, p.1-41, 2006. Disponível em:

<http://www.ufpa.br/epdir/images/docs/paper29.pdf>. Acesso em: 10 mar. 2018.

CURY, C. R. J. Direito à educação: direito à igualdade, direito à diferença. Cad. Pesqui., São Paulo, n. 116, p. 245-262, jul. 2002 . Disponível em:

$<$ http://www.scielo.br/scielo.php?script=sci arttext\&pid=S010015742002000200010\&lng=en\&nrm=iso>. Acesso em: 03 Set. 2018.

ESTADO DE SANTA CATARINA. Arranjos Produtivos Regionais/SC. [s.l.]: Diretoria de Políticas e Planejamento Educacional (DIPE), 2016. Disponível em:

$<$ http://www.uniedu.sed.sc.gov.br/wpcontent/uploads/2013/09/ArranjosProdutivosRegionais.pdf>. Acesso em: 07 nov. 2017.

FIGUEIREDO, M.; FIGUEIREDO, A. C. Avaliação Política e Avaliação de Políticas: Um Quadro de Referência Teórica. Revista Fundação João Pinheiro, Campinas, v. 1, n. 3, p. 108-129, set./dez. 1986. Disponível em: <http://www.josenorberto.com.br/ac-200738.pdf $>$. Acesso em: 10 mar. 2018.

FREY, K. Políticas Públicas: um debate conceitual e reflexões referentes à prática da análise de políticas públicas no Brasil. Planejamento e Políticas Públicas, [s.l.], n. 21, p. 212-259, jun. 2000. Disponível em:

<http://www.ipea.gov.br/ppp/index.php/PPP/article/view/89/158>. Acesso em: 17 jan. 2018.

INSTITUTO BRASILEIRO DE GEOGRAFIA E ESTATÍSTICA (IBGE). Censo Demográfico 2010: educação e deslocamento. 2010. Disponível em:

<https://ww2.ibge.gov.br/home/estatistica/populacao/censo2010/educacao e desloca mento/default xls.shtm>. Acesso em: 25 jan. 2018.

INSTITUTO FEDERAL CATARINENSE. Resolução ad referendum n. 21/2013

CONSUPER. Lex: Resoluções aprovadas em 2013, Blumenau, 2013 (a). Disponível em: $<$ http://consuper.ifc.edu.br/wpcontent/uploads/sites/14/2014/07/Resolu\%C3\%A7\%C3\%A3o-Ad-referendum-0212013-3.pdf >. Acesso em: 10 mar. 2018.

Resolução n. 48/2013 CONSUPER. Lex: Resoluções aprovadas em 2013, Blumenau, 2013 (b). Disponível em: <http://consuper.ifc.edu.br/wpcontent/uploads/sites/14/2014/07/RESOLU\%C3\%87\%C3\%830-048-2013-Aprovaad-ref.-021.pdf>. Acesso em: 10 mar. 2018. 
Relatório de Gestão do Exercício de 2016. Blumenau: IFC, 2017 (a). Disponível em: <http://ifc.edu.br/wp-content/uploads/2014/05/RELAT\%C3\%93RIO-2016.pdf>. Acesso em: 05 dez. 2017.

Sobre o IFC. 2017 (b). Disponível em: <http://ifc.edu.br/sobre-o-ifc/>. Acesso em: 04 out. 2017.

Relatório de gestão do exercício de 2017. Blumenau: IFC, 2018. 358 p. Disponível em: <http://ifc.edu.br/wp-content/uploads/2018/07/Relat\%C3\%B3rio-deGest\%C3\%A3o-2017.pdf>. Acesso em: 25 jul. 2018.

INSTITUTO FEDERAL CATARINENSE CAMPUS CONCÓRDIA (IFC). Projeto Pedagógico do Curso Técnico em Agropecuária Integrado ao Ensino Médio. 2015. Disponível em: <http://tecnico-agropecuaria.concordia.ifc.edu.br/wpcontent/uploads/sites/18/2016/10/ppc reformulado 2015.pdf >. Acesso em: $18 \mathrm{dez}$. 2017.

.Histórico. 2017 (a). Disponível em:

<http://concordia.ifc.edu.br/institucional/historico/>. Acesso em: 18 dez. 2017.

Cursos. 2017 (b). Disponível em: <http://concordia.ifc.edu.br/cursos/>. Acesso em 22 nov. 2017.

LINHARES, M.. Políticas públicas de inclusão social na América Latina: ações afirmativas no Brasil e México. 2010. 490 f. Tese (Doutorado) - Curso de Doutorado em Integração da América Latina, Universidade de São Paulo, São Paulo, 2010.

MARCHESAN, F.; OLIVEIRA, O. S. de. Ação Afirmativa para a Agricultura Familiar no Curso Técnico em Agropecuária do Instituto Federal Catarinense - Campus Concórdia: origem e motivação para sua criação. In: CONGRESSO INTERNACIONAL DE DESEMPENHO NO SETOR PÚBLICO, 1., 2017, Florianópolis. Anais... . Disponível em: $<$ http://cidesp.com.br/index.php/Icidesp/1cidesp/paper/view/242/15>. Acesso em: 27 de fev. 2018.

MCCOWAN, T. Expansion without equity: an analysis of current policy on access to higher education in Brazil. Higher Education, Londres, v. 53, n. 5, p. 579-598, 2007. Disponível em: <https://link.springer.com/article/10.1007/s10734-005-0097-4>. Acesso em: 15 mar. 2018.

MELLO, G. N. de. Políticas Públicas de educação. Estudos Avançados, São Paulo, v. 5, n. 13, p. 7-47, set./dez. 1991. Disponível em:

<http://www.scielo.br/scielo.php?script=sci arttext\&pid=S0103-

40141991000300002>. Acesso em 07 fev. 2018.

MENEZES, P. L. de. A ação afirmativa (Affirmative action) no direito norteamericano. São Paulo: Editora Revista dos tribunais, 2001. 174 p.

PORTAL DO CIDADÃO (Concórdia). A economia geral. Disponível em: <https://concordia.atende.net/\#!/tipo/pagina/valor/6>. Acesso em: 19 dez. 2017. 
SANO, H.; MONTENEGRO FILHO, M. J. F. As técnicas de avaliação da eficiência, eficácia e efetividade na gestão pública e sua relevância para o desenvolvimento social e das ações públicas. Desenvolvimento em Questão, [s.l.], v. 11, n. 22, p. 35-61, 2013.

SANTOS, M. A. de, et al. Memória IFC Campus Concórdia: 50 anos de registros e relatos. In: Mostra Nacional de Iniciação Científica e Tecnológica Interdisciplinar. 2015, Santa Rosa do Sul. Artigo. Disponível em: <http://eventos.ifc.edu.br/wpcontent/uploads/sites/5/2015/10/MEM\%C3\%93RIA-IFC-CAMPUSCONC\%C3\%93RDIA-50-ANOS-DE-REGISTROS-E-RELATOS.pdf $>$. Acesso em: $18 \mathrm{dez}$. 2017.

SECRETARIA DE EDUCAÇÃO PROFISSIONAL E TECNOLÓGICA (SETEC/MEC); INSTITUTO FEDERAL DE EDUCAÇÃO CIÊNCIA E TECNOLOGIA CATARINESE (IFC). Acordo de Metas e Compromissos. Brasília, 2010. Disponível em: <http://ifc.edu.br/wp-content/uploads/2014/10/MEC-SETEC-ACORDO-DE-METAS-ECOMPROMISSOS.pdf > . Acesso em: 10 mai. 2018.

SILVA, M. A. S. N. da; TORELLY, E.; MADEIRA, L. M. O Estado Social no Brasil, a Constituição Federal de 1988 e as políticas públicas criminais: (des) conformidades e (in) efetividades. In: IX Salão de Iniciação Científica PUCRS, 9, 2008, Porto Alegre. Artigo. 


\title{
JORNAL DE PoLíticas EducacionaIS

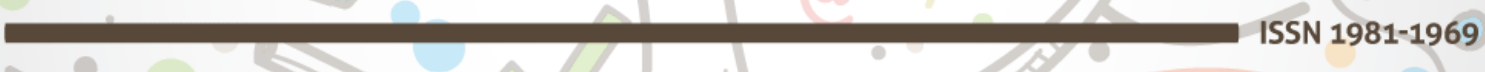 \\ Volume 13 \\ Número 36 \\ 20 de outubro de 2019
}

\begin{abstract}
(c)
SOREERIGHIS RESERVED O Copyright é retido pelo/a autor/a (ou primeiro co-autor) que outorga o direito da primeira publicação ao Jornal de Políticas Educacionais. Mais informação da licença de CreativeCommons encontram-se em http://creativecommons.org/licenses/by-nc-nd/2.5. Qualquer outro uso deve ser aprovado em conjunto pelo/s autor/es e pelo periódico.

JoRnAL DE POLÍTICAS EdUCACIONAIS é uma publicação do Núcleo de PolíticasEducacionaisdo Setor de Educação da Universidade Federal do Paraná - NuPE/UFPR, em consórcio com a Linha de Pesquisa em Políticas Educacionais do Programa de Pós-Graduação em Educação - PPGE/UFPR, que aceita colaboração, reservando-se o direito de publicar ou não o material espontaneamente enviado à redação. As colaborações devem ser enviadas ao NuPE/UFPR, conforme orientações contidas nas páginas do periódico na internet: http://revistas.ufpr.br/ipe.
\end{abstract}

\author{
Indexação: \\ BBE - Biblioteca Brasileira de Educação (MEC/INEP) \\ Clase (Base de Datos Bibliográfica de Revistas de Ciencias Sociales y Humanidades) \\ Diadorim - Diretório de Política de Acesso Aberto das Revistas Científicas Brasileiras (IBICT) \\ Google Scholar \\ Index Copernicus \\ Portal de Periódicos (CAPES) \\ SER - Sistema Eletrônico de Revistas da Universidade Federal do Paraná (SER/UFPR) \\ Sumários de Revistas Brasileiras (FUNPEC-RP) \\ DRJI - Directory of Research Journals Indexing
}

(Periódico integralmente disponível apenas em via eletrônica)

Jornal de Políticas Educacionais / Núcleo de Políticas Educacionais da Universidade Federal do Paraná NuPE/UFPR - v.1, n. 1 (1ํㅗ을 semestre de 2007) - Curitiba: NuPE/UFPR.

Volume 13, número 36 - Outubro de 2019

ISSN 1981-1969

1. Educação - Periódicos. 2. Política Educacional - Periódicos. I. NuPE/UFPR

Comitê Editorial:

Elisângela Scaff (UFPR)

Daniela Oliveira Pires (UFPR)

Conselho Editorial:

Andréa Barbosa Gouveia (UFPR - Brasil), Cesar Tello (Universidad Nacional Tres Febrero, Argentina), Fernanda Saforcada (Universidad de Buenos Aires - UBA - Argentina), Gladys Beatriz Barreyro (USP Brasil), Gustavo Enrique Fischman, (Arizona State University - USA), Jefferson Mainardes (UEPG - Brasil), João Ferreira de Oliveira (UFG - Brasil), Juca Gil (UFRGS - Brasil), Luiz Souza Júnior (UFPB - Brasil), Ney 
MARCHESAN, F.; OLIVEIRA, O. S de. Avaliação da efetividade de uma política pública: ação afirmativa para a agricultura familiar no Campus Concórdia/IFC

Cristina Monteiro de Oliveira (UFPA - Brasil), Nicolás Bentancur, (Universidad de la República de Uruguay), Robert Verhine (UFBA - Brasil), Rosana Cruz (UFPI - Brasil), Rubens Barbosa Camargo (USP - Brasil), Sebastián Donoso Díaz (Universidad de Talca - Chile), TheresaAdrião (UNICAMP - Brasil), Vera Peroni (UFRGS - Brasil).

Créditos e Agradecimentos:

Revisão de Língua Portuguesa, Abstract e Resumen: PROGRAMA DE APOIO ÀS PUBLICAÇÕES CIENTÍFICAS PERIÓDICAS DA UFPR

Arte e diagramação: TIAGO TAVARES (thiagotav@gmail.com)

Jornal de Políticas Educacionais

Universidade Federal do Paraná

Setor de Educação

Núcleo de Políticas Educacionais - NuPE/UFPR

Avenida Sete de Setembro, 2645

$2^{\circ}$ andar, Sala 213

80.230-010 - Curitiba - PR - Brasil

Tel.: 41-3535-6264

jpe@ufpr.br

http://revistas.ufpr.br/jpe 